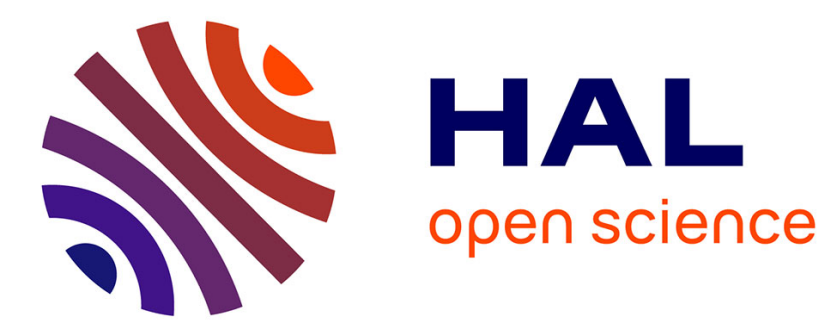

\title{
CHARACTERIZATION OF POLYCRYSTALLINE SILICON BY EBIC
}

\author{
M. Kittler, J. Lärz, G. Morgenstern, W. Seifert
}

\section{To cite this version:}

M. Kittler, J. Lärz, G. Morgenstern, W. Seifert. CHARACTERIZATION OF POLYCRYSTALLINE SILICON BY EBIC. Journal de Physique IV Proceedings, 1991, 01 (C6), pp.C6-173-C6-179. 10.1051/jp4:1991626 . jpa-00250711

\section{HAL Id: jpa-00250711 https://hal.science/jpa-00250711}

Submitted on 1 Jan 1991

HAL is a multi-disciplinary open access archive for the deposit and dissemination of scientific research documents, whether they are published or not. The documents may come from teaching and research institutions in France or abroad, or from public or private research centers.
L'archive ouverte pluridisciplinaire HAL, est destinée au dépôt et à la diffusion de documents scientifiques de niveau recherche, publiés ou non, émanant des établissements d'enseignement et de recherche français ou étrangers, des laboratoires publics ou privés. 
JOURNAL DE PHYSIQUE IV

Colloque C6, supplément au Journal de Physique III, Vol. 1, décembre 1991

\title{
CHARACTERIZATION OF POLYCRYSTALLINE SILICON BY EBIC
}

\author{
M. KITTLER, J. LÄRZ, G. MORGENSTERN and W. SEIFERT \\ Institut für Halbleiterphysik, PF 409, D-1200 Frankfurt (Oder), Germany
}

\begin{abstract}
The paper presents diffusion-length and contrast data for large-grained polycrystalline silicon. Rapid thermal annealing was observed to improve the material quality whereas conventional annealing in evacuated quartz ampoules made the material worse. Evidence for significant potential barriers and conduction at certain grain boundaries and for gettering action of defects was found.
\end{abstract}

1. - Introduction.

The demand for low-cost solar cells has led to application of cheap silicon materials in solar cell production. Cast polycrystalline silicon like Wacker Silso is widely used in this field. A certain disadvantage of this and similar materials is the existence of a large number of electrically active defects which may degrade solar cell efficiency. Thus, measures for suppression of defects respectively reduction of recombination activity of defects are of large interest. To provide the deeper knowledge required for this, detailed studies on generation, interaction and properties of defects in polycrystaline silicon for solar cells are carried out with different methods. Among them EBIC is a very important diagnostic tool as it provides information related directly to solar cell efficiency.

The material investigated in this study was p-type $(\approx 10 \Omega \mathrm{cm})$ Wacker silso. The following heat treatments were used to influence the recombination properties of the material: (i) annealing at $1000^{\circ} \mathrm{C}$ in evacuated quartz ampoules followed by either slow cooling down in air or quenching in water and (ii) rapid thermal annealing in oxygen atmosphere. Before annealing the samples were lapped and polished. Schottky contacts were prepared by Al evaporation and ohmic contacts by rubbing on Ga. In some cases an additional chemical polish preceded the Schottky contact preparation. To allow easy evaluation of changes due to annealing two parallel samples having nearly identical defect structure were compared in each case, one in the as-grown state and the other after annealing.

The following two chapters discuss both methodical aspects and results of diffusion-length (DL) measurements and determination of electrical activity of defects in the material investigated. 
2. - Diffusion length studies.

\section{1. - Methodical aspects.}

The known EBIC techniques for DL determination can be grouped into methods based on measuring the EBIC decay at a given beam energy $E_{0}$ and into the energy-dependent method based on measuring the collection efficiency $\eta$ as a function of $E_{0} / 1 /$. Measurements using decay methods require homogeneous material or well isolated defects. For the polycrystalline material studied here decay methods are rather not applicable due to high defect density and inhomogeneity of recombination properties (compare Fig. 5). The best technique for this material is the $\eta\left(E_{0}\right)$ technique because of compatibility with defect imaging, possibility of averaging over a certain area, and relatively high lateral resolution. Another advantage of the $\eta\left(E_{0}\right)$ method arises from the possibility of DL depth profiling at bevels /2/, which may be important when procedures for improving the solar cell efficiency are to be developed.

This technique has, however, the serious drawbacks of necessity of absolute measurements of beam current, $I_{b}$, and collected current, $I_{E \text { в }} c$, and of large time consumption due to repeated $I_{b}$ and $I_{E B}$ c measurements at a large set of different beam energies. These disadvantages can be overcome in some cases looking at the decay of the $\eta\left(E_{0}\right)$ curve at large $E_{0}$. Fig. 1 shows the calculated steepness of the curve between 30 and $40 \mathrm{keV}, S=\eta(30) / \eta(40)-1$, as a function of diffusion length $L$. A Schottky contact with top layer thickness $\mathrm{m}=0.1 \mu \mathrm{m}$ and depletion layer width $w=0.5 \mu \mathrm{m}$ was assumed. Changes of $\mathrm{m}$ and $w$ by $50 \%$ have a small only effect on $S$, so $S$ can be used to estimate $L$.

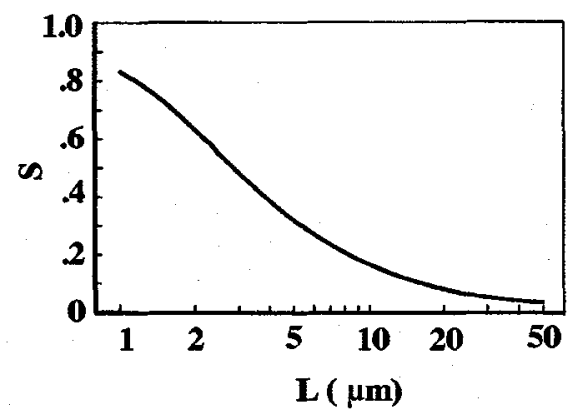

Fig. 1. - Calculated steepness of the $\eta\left(E_{0}\right)$ curve between 30 and $40 \mathrm{keV}$.

In practice, the method works well for $L<15 \mu \mathrm{m}$. For large $\mathrm{L}$ this simple method cannot be recommended, however. Experimental uncertainties in $\eta(30 \mathrm{keV})$ and $\eta(40 \mathrm{keV})$ will strongly influence the experimentally determined steepness and thus lead to large errors in L. Measurements at a third beam energy might help to increase the reliability of the experimental s figure.

The theoretical dependence given in Fig. 1 was the base of a concept for estimation of $L$ using an image processing system. According to the idea two EBIC images taken at 30 and $40 \mathrm{keV}$ are stored in an image processing system together with a calibration of the grey level scale in terms of collected current. Additionally, the beam current has to be measured at each beam energy. Under appropriate conditions the data collected this way about a certain sample area should allow then to determine and correlate local DL, average DL, defect contrasts and defect density/distribution. 


\section{2. - Results.}

The as-grown samples showed large variations of DL in accordance with the local defect structure and density. The diffusion length in small defect-free regions was close to figures known for high quality monocrystalline silicon, whereas DL below $5 \mu \mathrm{m}$ could be found in regions of high defect density. This density dependence is in qualitative agreement with an often found proportionality between DL and distance of defects $/ 3,4 /$ and demonstrates the dominating role of extended defects in the as-grown state.

The effect of annealing is illustrated in Table 1 . The couples of DL figures (before and after annealing) were measured in parallel samples and refer to the same region. Ampoule annealing is found to decrease DL in an unexpected way. Namely, regions of low defect density and initially high DL may exhibit lower DL than regions of high defect density. This can lead to a contrast inversion in the EBIC images (compare Fig. $2 a$ and $b)$ and should be understood as indication of effective gettering of impurities in regions of high defect density. In defectfree regions these impurities remain active and cause a strong DL reduction.

Rapid thermal annealing, on the other hand, improves the diffusion length significantly (compare Fig. $3 a$ and $b$ ).

Table 1. - Illustration of DL changes in regions of low and high defect density caused by annealing in evacuated ampoules and by rapid thermal annealing, respectively.

\begin{tabular}{|c|c|c|c|c|}
\hline defect density & $\begin{array}{l}\text { ampoule } \\
\text { before }\end{array}$ & $\begin{array}{r}\text { annealing } \\
\text { after }\end{array}$ & $\begin{array}{c}\text { rapid thermal } \\
\text { before }\end{array}$ & $\begin{array}{c}\text { annealing } \\
\text { after }\end{array}$ \\
\hline low & $\mathrm{L} \approx 30 \mu \mathrm{m}$ & $L \approx 3.5 \mu \mathrm{m}$ & $L \approx 20 \mu \mathrm{m}$ & $\mathrm{L} \approx 50 \mu \mathrm{m}$ \\
\hline high & $\mathrm{L} \approx 9 \mu \mathrm{m}$ & $L \approx 6 \mu \mathrm{m}$ & $L \approx 4 \mu \mathrm{m}$ & $\mathrm{L} \approx 14 \mu \mathrm{m}$ \\
\hline
\end{tabular}

3. - Defect investigations.

3.1. - Influence of annealing on defect contrasts.

Similar to effects on DL, the different annealing procedures applied have pronounced effects on defect contrast, too. In the as-grown material all defects appear dark, the strongest contrasts exceeding $c=0.4$. After the annealing in ampoules bright contrasts arise around grain boundaries (GB's) and defect agglomerations (Fig. 2b). The width of the bright zones depends on the cooling rate and is larger for slowly cooled samples. The profiles in Fig. 2d show that the collection efficiency has significantly dropped compared to the as-grown state and that the area under the bright-contrast part of the profile is larger than that of the central dark-contrast part. This is in agreement with the DL data reported, in particular with higher DL in regions of high defect density. All these findings can be understood in terms of gettering of impurities (introduced into the sample or released from defects during annealing) by defects and a following at least partial transformation of the impurities into an inactive state. Regions of low defect density or without defects remain at a high impurity level and appear darker therefore. 
a

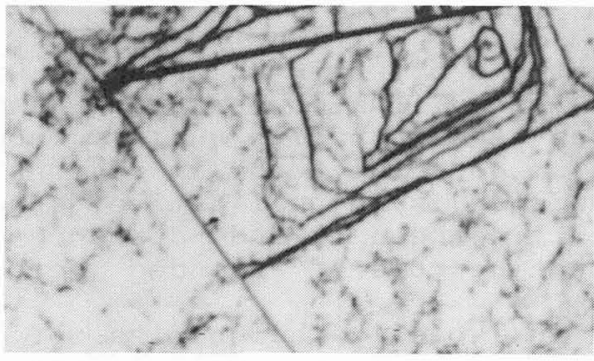

$300 \mathrm{~K}$

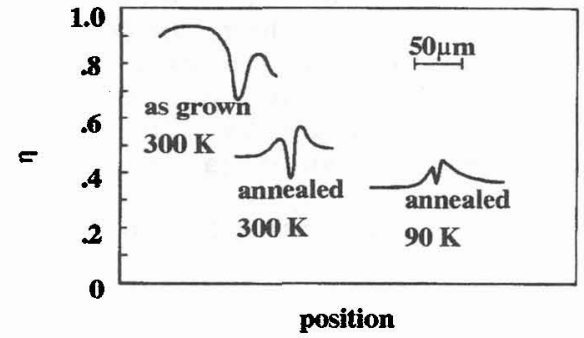

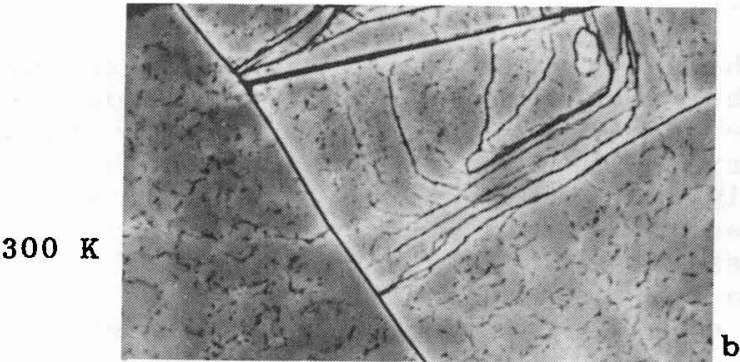

b

\section{$0.5 \mathrm{~mm} \longmapsto$}

Fig. 2. - Effect of ampoule annealing followed by quenching in water on recombination properties: a) and b) EBIC micrographs ( $\left.E_{0}=30 \mathrm{keV}\right)$ at $300 \mathrm{~K}$ of the as-grown and annealed sample, respectively, c) EBIC micrograph ( $E_{0}=30 \mathrm{keV}$ ) at $90 \mathrm{~K}$ of the annealed sample, and d) collection efficiency profiles perpendicular to the grain boundary marked by an arrow.

$\mathbf{a}$

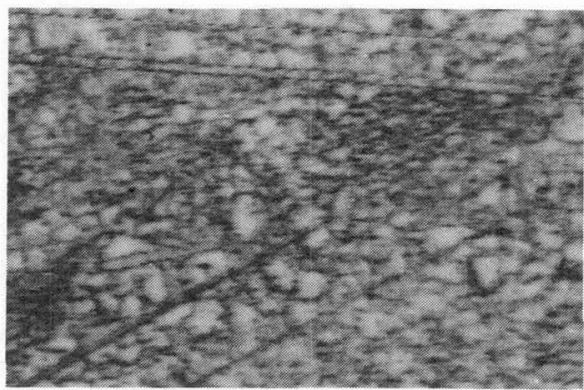

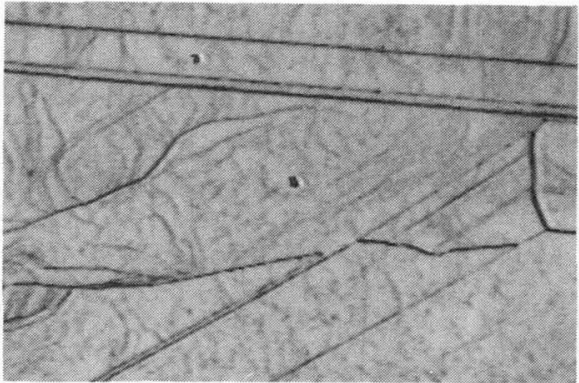

b

$1 \mathrm{~mm} \longmapsto$

Fig. 3. - Effect of rapid thermal annealing on recombination properties $\left(E_{0}=30 \mathrm{keV}, 300 \mathrm{~K}\right):$ a) as-grown state, b) annealed state.

The annealed material exhibits clear changes in the EBIC micrographs on cooling the sample down to $90 \mathrm{~K}$ (Fig. 2c), although no significant changes were observed for the as-grown material. The dominating effect is an increasing weight of bright getter zones around defects and a decrease of dark contrasts. The corresponding profile in Fig. 2d shows that the current collected at the GB is no longer below the current collected outside the bright-contrast zone, $i$. e. if we define contrast $c$ in relation to the current well away from the GB then $c$ is close to zero. To summarize, the GB with dark contrast of $c \approx 0.28$ in the asgrown state gives rise to a bright/dark contrast of $c \approx-0.20 / c \approx 0.25$ 
at $300 \mathrm{~K}$ and to bright/dark contrast of $c \approx-0.25 / \mathrm{c} \approx 0$ at $90 \mathrm{~K}$ after annealing. An additional effect observed at $T=90 \mathrm{~K}$ is a zone of low EBIC signal surrounding the well developed bright zones at the GB considered before. Further, defect-free regions appearing dark at room temperature are imaged as regions of slightly incrased EBIC signal at $T=90 \mathrm{~K}$. An interpretation of these temperature-dependent results is difficult at the present stage.

Contrary to annealing in ampoules, rapid thermal annealing is found to reduce the activity of intragrain defects whereas grain boundaries seem to maintain or even increase their activity (Fig. $3 a, b$ ).

The reasons of the annealing-caused contrast changes are not yet clear. Continuation of TEM investigations, including direct EBIC/TEM correlation, is required to get a microscopic insight into the processes involved.

\section{2. - Influence of contacting.}

Some of the first temperature-dependent EBIC measurements of the samples studied revealed dramatic changes in electrical activity (Fig. 4). Fig. 4 b shows adjacent grains behaving very differently at temperature $T=90 \mathrm{~K}$ and $\mathrm{T}$ GB imaged as bright line outside the Schottky contact area. Later it turned out that the appearance of bright GB contrasts outside the Schottky contact area is not limited to low temperatures. The bright contrast demonstrates that GB's are able to collect and transport charge carriers. Similar bright contrasts at GB's caused by charge collection have been reported for n-type silicon in /5/ already.

a
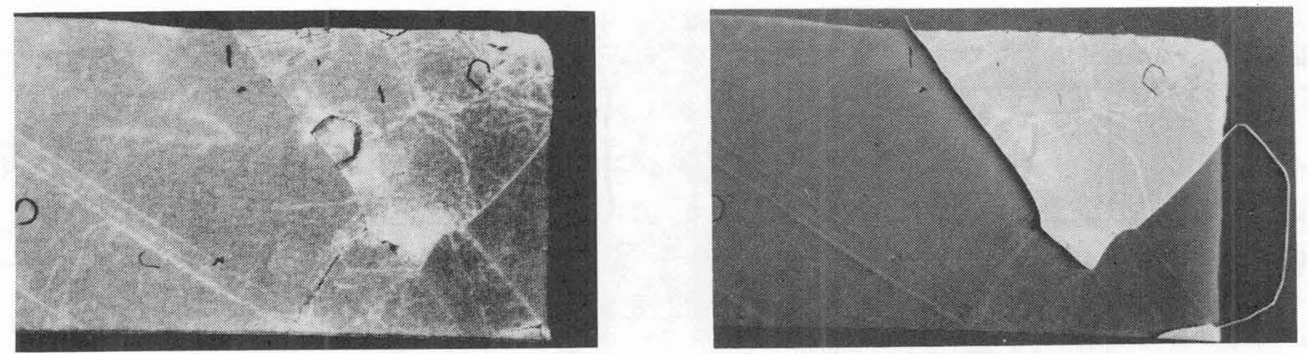

$\mathbf{b}$

$2 \mathrm{~mm} \longmapsto$

Fig. 4. - Temperature-dependent EBIC investigation demonstrating different behaviour of grains and charge collection at GB outside the contact area ( $\left.\mathrm{E}_{0}=30 \mathrm{keV}\right)$ : a) $300 \mathrm{~K}$, b) $90 \mathrm{~K}$.

More detailed investigations led to the result that the way of contacting the sample has a strong influence on the behaviour observed (Fig. 5). It could be shown that normal behaviour of grains under the Schottky contact can be obtained at low $T$ when providing a large ohmic contact to the back surface of the sample, while contacting only one grain results in similar effects as in Fig. 4. The reason might be that at low $T$ certain GB' $s$ act as barriers to majority carriers and hinder the charge flow between Schottky and ohmic contact. The grains not contacted show a low EBIC signal therefore.

If it is true that GB's possess a potential barrier it should be possible to obtain an EBIC signal at the GB site when contacting adjacent grains ohmically /6/. Fig. 6 demonstrates that this is really the case. Fig. 6 e presents a well resolved image and the corresponding line profile of the EBIC signal of a GB at $300 \mathrm{~K}$ (to improve resolution the image was taken after irradiating the area of interest with a high beam current which increases recombination at the free surface). 


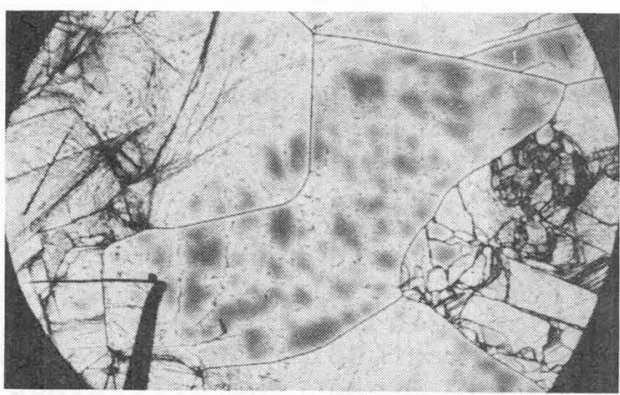

$300 \mathrm{~K}$
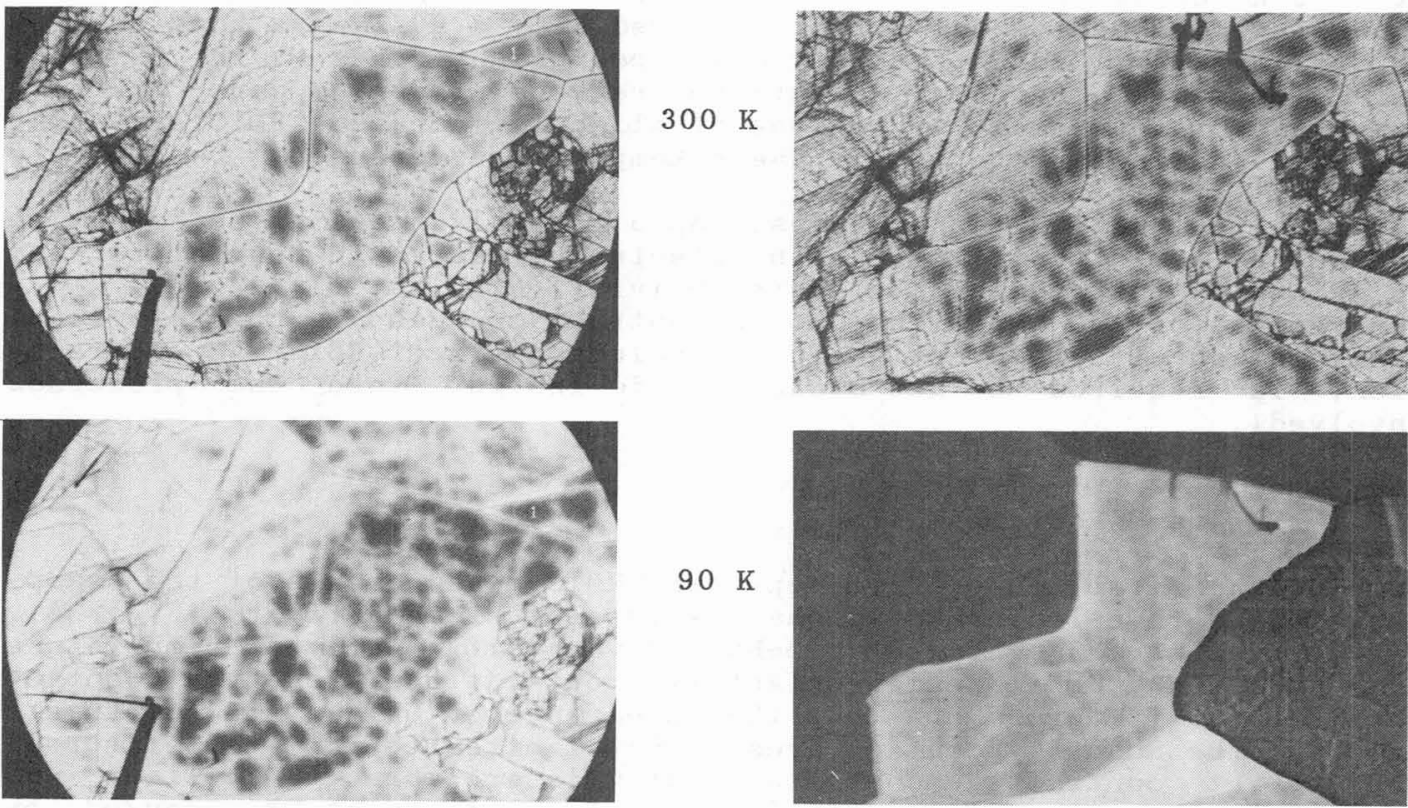

$1 \mathrm{~mm} \longmapsto$
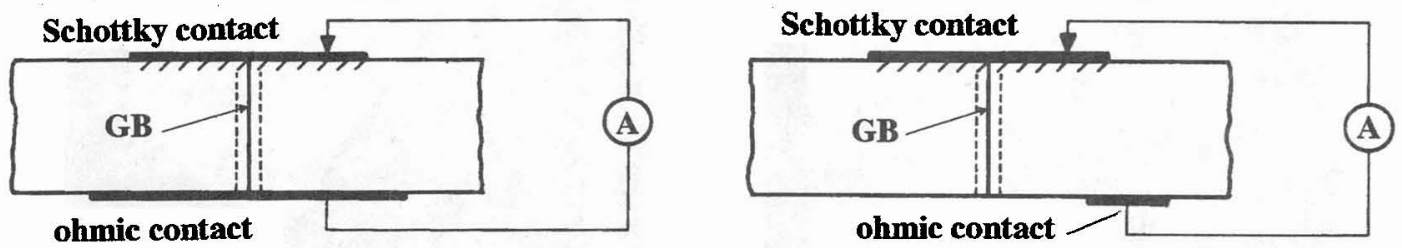

Fig. 5. - Illustration of the influence of ohmic contacting on results of temperature-dependent EBIC investigations ( $E_{0}=30 \mathrm{keV}$ ); left row large area ohmic contact, right row - ohmic contact to one grain only.

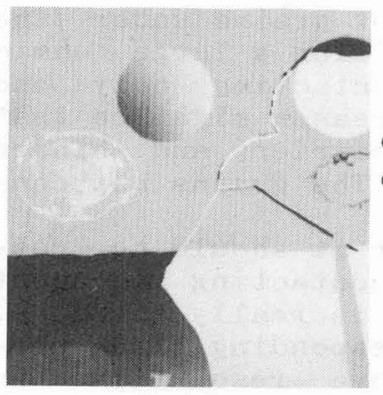

a

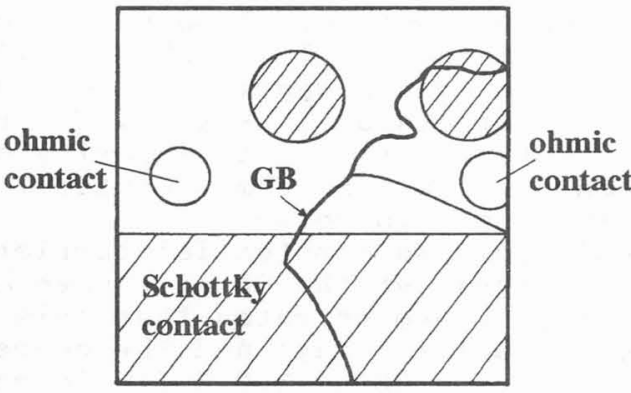

b

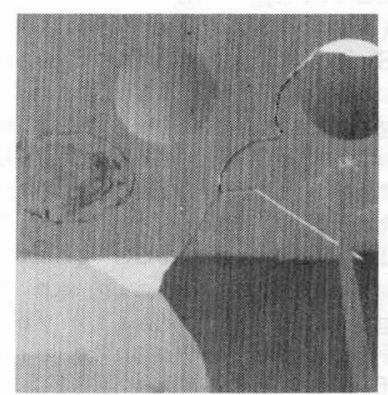

c

(Fig. 6 continued next page) 


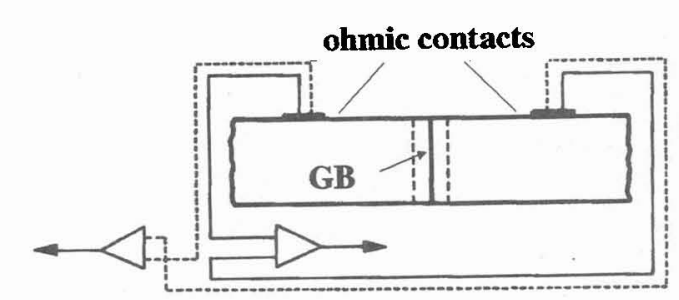

d

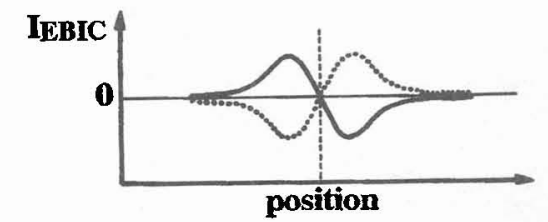

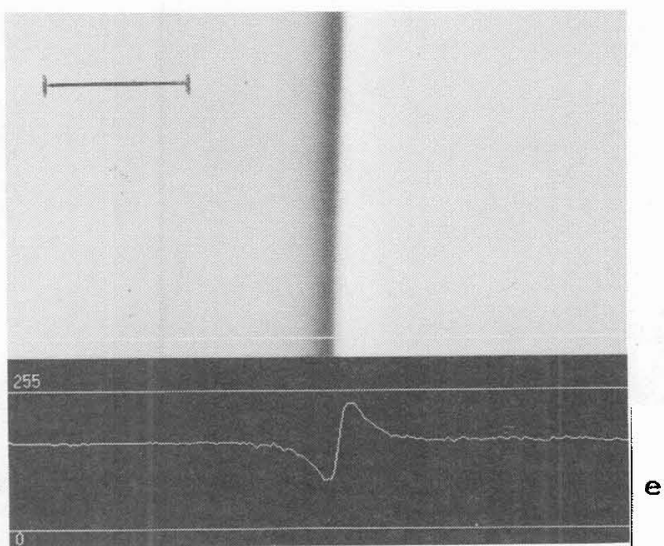

Fig. 6. - EBIC investigations of a polycrystalline sample at $300 \mathrm{~K}$
using contacting after $/ 6 /$ a) and $\mathrm{c}$ ) with additional schottky contacts present, micrographs $\left(E_{0}=30 \mathrm{keV}\right)$ differing due to opposite connection to the amplifier; b) schematic illustration to a) and c); d) schematic of contacting after $/ 6 /$; e) micrograph $\left(E_{0}=10 \mathrm{keV}\right)$ and current profile across a grain boundary, bar: $10 \mu \mathrm{m}$.

In case additional Schottky contacts cover a part of the GB studied, significant EBIC signal of different sign is observed on the Schottky contact on both sides of the GB (Fig. 6a,c). One may conclude that the GB must have provided a conduction path to carriers because the Schottky contacts were not connected to the amplifier. This might explain the poor blocking characteristics of Schottky diodes prepared on the polycrystalline samples.

To summarize, certain GB's in both the as-grown and annealed samples have significant potential barriers and collect minority carriers. The experiments with Schottky contacts seem to indicate a conduction along GB's, too. The details of the effects observed are, however, not understood in detail so far.

Acknowledgement: The authors acknowledge the support by Dr. A. Räuber and Dr. A. Hurrle at FhG ISE, Freiburg and by the Bundesministerium für Forschung und Technologie, Bonn under contract No. 0329107F.

/1/ KITTLER, M. and SEIFERT W., Rev. Physique Appliquee 24 (1989) C6-47

/2/ DONOLATO, C. and KITTLER, M. , J. Appl. Phys.63 (1988) 1569

/3/ KITTLER, M. and SEIFERT, W., Scanning Microsc, 2 (1988) 1397, KITTLER, M. , LARZ, J., SEIFERT, W. , SEIBT M., and SCHRరTER, W. , App1. Phys. Lett. 58 (1991) 911

/4/ JASTRZEBSKI, L., Mater. Sci. Eng. B4 (1989) 113

/5/ KOLBE, M., HOLLRICHER, O., GOTTSCHALK, H. , and ALEXANDER, H., Inst. Phys. Conf. Ser. 100 (1989) 725

/6/ MATARE, H.F. and LAAKSO, C.W., J. Appl. Phys. 40 (1969) 476 